\title{
Comparison of Dexamethasone and Tramadol as Adjuvant to Levobupivacaine in Supraclavicular Block
}

\author{
Manu Seth ${ }^{1}$, Rajeev Das ${ }^{2}$, Rubal Singhal ${ }^{1}$ \\ ${ }^{1}$ Assistant Professor, Department of Anaesthesia, TS Mishra Medical College, Lucknow, UP, ${ }^{2}$ Associate Professor, Department of Anaesthesia, TS Mishra \\ Medical College, Lucknow.
}

\section{Abstract}

Background: Supraclavicular block is one of the most effective anaesthetic procedures in an operation of upper extremity. The present study was conducted to evaluate and compare dexamethasone and tramadol as adjuvant to levobupivacaine in supraclavicular block. Subjects and Methods: The present study was conducted in the department of Anaesthesiology. It comprised of 50 patients of American Society of Anaesthesiologists (ASA) grade I and II of age group 18 - 60 years of either sex. Group I $(n=25)$ in which 30 ml of $0.5 \%$ levobupivacaine hydrochloride plus $2 \mathrm{ml}$ tramadol (100mg) was used. Group II (n=25) in which $30 \mathrm{ml}$ of $0.5 \%$ Levobupivacaine hydrochloride plus $2 \mathrm{ml}$ dexamethasone $(8 \mathrm{mg}$ ) was used. In both groups, sensory block, motor block and complications were recorded. Results: The mean duration of sensory block in group I was 13.41 hours and in group I was 15.28 hours, motor block was 14.52 hours in group I and 17.45 hours in group II and duration of analgesia was 16.15 hours in group I and 19.26 hours in group II. The difference was significant $(\mathrm{P}<0.05)$. Common complication recorded was intravascular injection, hoarseness, hypotension and bradycardia in both groups. The difference was significant $(\mathrm{P}<$ 0.05). Conclusion: Dexamethasone is a better adjuvant than tramadol when added to levobupivacaine in supraclavicular brachial plexus block.

Keywords: Dexamethasone, Supraclavicular, Tramadol.

Corresponding Author: Dr. Rajeev Das, Assistant Professor, Department of Anaesthesia, TS Mishra Medical College, Lucknow.

Received: October 2019

Accepted: October 2019

\section{Introduction}

Since the discovery of anesthetic agents, various modes of anaesthesia have developed till now like general anaesthesia, local anaesthesia, spinal anaesthesia, epidural anaesthesia, intravenous anaesthesia and peripheral nerve blocks. ${ }^{[1]}$ Anaesthetic agents are available in the form of gases, injections and jellies. The American board of anesthesiology lists "the aim of post-operative pain relief is to prevent subjective discomfort in addition to early mobilization and shortened hospital stay and subsequently to enhance restoration of physiological function of operated region. ${ }^{[2]}$

Supraclavicular block is one of the most effective anaesthetic procedures in an operation of upper extremity. ${ }^{[3]}$ The supraclavicular block is often called as spinal anaesthesia of upper extremities because of ubiquitous application for upper extremity surgeries. The reason for its high success rate is in its anatomic characteristics. ${ }^{[4]}$ Winnie's approach using nerve locator is a very popular mode of anaesthesia for various upper limb surgeries. ${ }^{[5]}$ This approach is attractive due to its effectiveness in term of cost and performance, margin of safety along with good post-op analgesia. The block is performed at the level of distal trunks and origin of the divisions where brachial plexus is confined to the smallest surface area. Many approaches have been proposed for supraclavicular block. ${ }^{[6]}$ The present study was conducted to evaluate and compare dexamethasone and tramadol as adjuvant to levobupivacaine in supraclavicular block.

\section{Subjects and Methods}

The present study was conducted in the department of Anaesthesiology. It comprised of 50 patients of American Society of Anaesthesiologists (ASA) grade I and II of age group 18 - 60 years of either sex, scheduled to undergo surgery of the forearm or hand under supraclavicular brachial plexus block with levobupivacaine with addition of dexamethasone and dexmedetomidine as adjutants were included. The approval of Institutional Ethics Committee was taken. A written consent was taken from all the participants.

General information such as name, age, gender etc. was recorded. Patients were divided into 2 groups. Group I $(\mathrm{n}=25)$ in which $30 \mathrm{ml}$ of $0.5 \%$ levobupivacaine hydrochloride plus $2 \mathrm{ml}$ tramadol (100mg) was used. Group II $(n=25)$ in which $30 \mathrm{ml}$ of $0.5 \%$ Levobupivacaine hydrochloride plus $2 \mathrm{ml}$ dexamethasone $(8 \mathrm{mg}$ ) was used. In both groups, sensory block, motor block and complications were recorded. The data was compiled and statistically analyzed. $\mathrm{P}$ value of less than 0.05 was considered significant. 
0

\section{Results}

Table 1: Distribution of patients

\begin{tabular}{|l|l|l|}
\hline Groups & Group I & Group I \\
\hline Agent & $\begin{array}{l}0.5 \% \text { levobupivacaine } \\
\text { hydrochloride plus 2 } \mathrm{ml} \\
\text { tramadol }\end{array}$ & $\begin{array}{l}0.5 \% \text { Levobupivacaine } \\
\text { hydrochloride plus 2 } \mathrm{ml} \\
\text { dexamethasone }\end{array}$ \\
\hline Number & 25 & 25 \\
\hline
\end{tabular}

[Table 1] shows that group I consisted of $0.5 \%$ levobupivacaine hydrochloride plus $2 \mathrm{ml}$ tramadol was used. Group II consisted of $0.5 \%$ levobupivacaine hydrochloride plus $2 \mathrm{ml}$ dexamethasone. Each group had 25 patients each.

Table 2: Comparison of parameters
\begin{tabular}{|l|l|l|l|}
\hline Duration (hours) & Group I & Group II & P value \\
\hline Sensory block & 13.41 & 15.28 & 0.01 \\
\hline Motor block & 14.52 & 17.45 & 0.02 \\
\hline $\begin{array}{l}\text { Duration of } \\
\text { analgesia }\end{array}$ & 16.15 & 19.26 & 0.04 \\
\hline
\end{tabular}

[Table 2], Graph I shows that mean duration of sensory block in group I was 13.41 hours and in group I was 15.28 hours, motor block was 14.52 hours in group I and 17.45 hours in group II and duration of analgesia was 16.15 hours in group I and 19.26 hours in group II. The difference was significant $(\mathrm{P}<0.05)$.

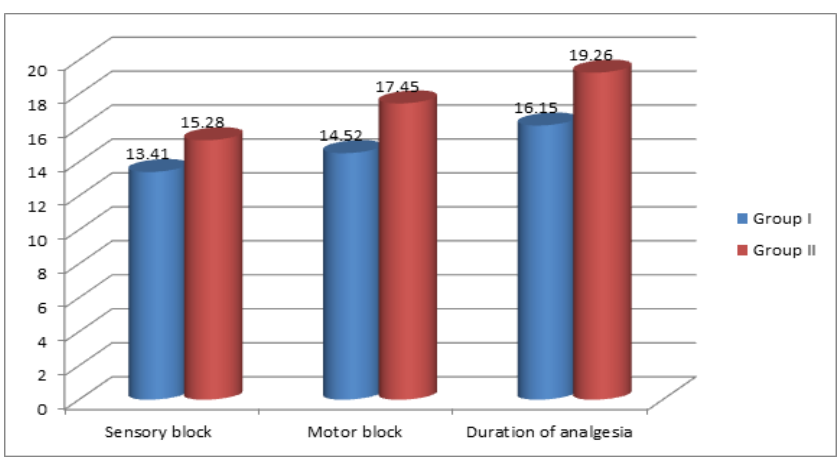

Figure 1: Comparison of parameters

Table 3: Side effects and complications in both groups

\begin{tabular}{|l|l|l|l|}
\hline Side effects & Group I & Group II & P value \\
\hline Intravascular injection & 2 & 1 & 0.01 \\
\hline Hoarseness & 1 & 2 & 0.01 \\
\hline Hypotension & 3 & 4 & 0.05 \\
\hline Bradycardia & 2 & 2 & 1 \\
\hline
\end{tabular}

[Table 3 \& Figure 2] shows that common complication recorded were intravascular injection, hoarseness, hypotension and bradycardia in both groups. The difference was significant $(\mathrm{P}<0.05)$.

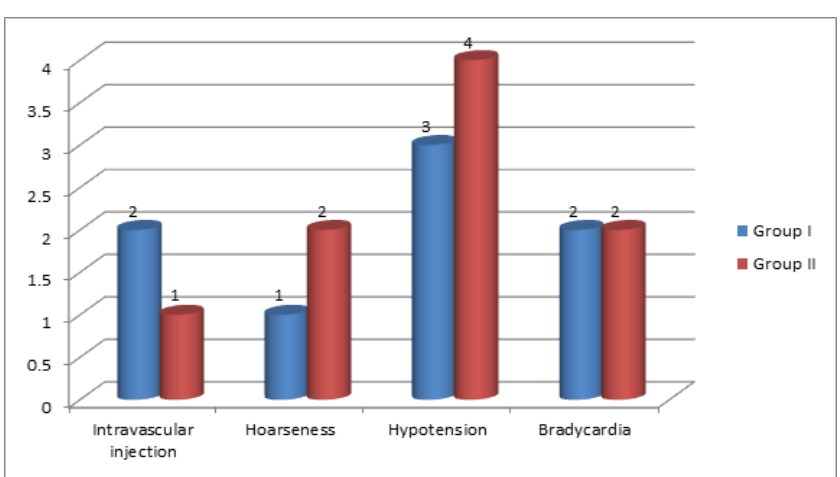

Figure 2: Side effects and complications in both groups

\section{Discussion}

Brachial plexus block is an excellent method for attaining optimal operating conditions for upper limb surgeries by producing complete muscular relaxation, maintaining haemodynamic stability and the associated sympathetic block. ${ }^{[7]}$ They also provide extended postoperative analgesia with minimal side effects. ${ }^{[8]}$ In addition, it offers a better preservation of mental functions in elderly; decreased risk of aspiration due to intact pharyngeal and laryngeal reflexes; avoids difficult intubation; decreases postoperative complications associated with intubation and provides better postoperative analgesia without undue sedation facilitating early mobilization and discharge. ${ }^{[9]}$ The present study was conducted to evaluate and compare dexamethasone and tramadol as adjuvant to levobupivacaine in supraclavicular block.

In this study, group I consisted of $0.5 \%$ levobupivacaine hydrochloride plus $2 \mathrm{ml}$ tramadol was used. Group II consisted of $0.5 \%$ levobupivacaine hydrochloride plus $2 \mathrm{ml}$ dexamethasone. Each group had 25 patients each. Arish et $\mathrm{al},{ }^{[10]}$ included 60 patients in the age group of 18-65 years belonging to ASA physical status I or II were included in the study. They are randomly allocated in two groups and each group included 30 patients. In group 1, patients received $30 \mathrm{ml}$ of $0.5 \%$ isobaric levobupivacaine with $2 \mathrm{ml}$ of isotonic sodium chloride. In group 2 patients received $8 \mathrm{mg}(2 \mathrm{ml})$ dexamethasone in addition to $30 \mathrm{ml}$ of $0.5 \%$ isobaric levobupivacaine. The results showed that the onset of sensory and motor block were faster in group $2(p<0.05)$. The duration of sensory and motor block were significantly longer in group $2(\mathrm{p}<0.05)$. VAS score at 12 hours were significantly lower in group $2(\mathrm{p}<0.05)$. None of the patients had bradycardia, hypotension or any other side effects.

We found that mean duration of sensory block in group I was 13.41 hours and in group I was 15.28 hours, motor block was 14.52 hours in group I and 17.45 hours in group II and duration of analgesia was 16.15 hours in group I and 19.26 hours in group II. Baloda et al, ${ }^{[11]}$ conducted a study in which patients were randomly divided in group A (40 ml volume of lignocaine $2 \%$ with adrenaline (1:200000) $+0.5 \%$ bupivacaine) and group B (40 ml volume of lignocaine $2 \%$ with adrenaline $(1: 200000)+0.5 \%$ bupivacaine with dexamethasone $8 \mathrm{mg}$ ). The onset and duration of sensory and motor block as well as duration of analgesia in the two groups were compared and any complications of the procedure were noted. Group B had early onset and prolonged duration of sensory and motor block as well as prolonged duration of analgesia as compared to group A. None of the patients had bradycardia, hypotension or any other side effects.

We found that common complication recorded were intravascular injection, hoarseness, hypotension and bradycardia in both groups. Choi et al, ${ }^{[12]}$ in their study sixty adult patients undergoing various orthopaedic surgeries on forearm and around the elbow under supraclavicular brachial plexus block were selected and divided into 2 groups of 30 each. In group-A patients received $35 \mathrm{ml}$ of mixture of lignocaine $2 \%$, bupivacaine $0.5 \%$ while in group-B patients received the same amount of local anaesthetics with 
0

dexamethasone $(8 \mathrm{mg})$. The mean onset time of sensory block was $11.64 \pm 2.19$ minutes in group $\mathrm{A}$ and $9.89 \pm 1.97$ minutes in group B and difference was statistically significant $(\mathrm{p}<0.05)$. Onset of motor block was $13.32 \pm 0.98$ minutes in group A and 11.09 \pm 1.28 minutes in group B and difference was statistically significant $(\mathrm{p}<0.05)$. There was markedly prolonged duration of analgesia in group-B, $11.87 \pm$ 0.53 hours compared to group- $\mathrm{A}, 3.43 \pm 0.49$ hours. The result was statistically highly significant $(\mathrm{p}<0.001)$. Both the groups had high success rate $(>90 \%)$. The incidence of complication was low in both the groups.

\section{Conclusion}

Authors found that dexmedetomidine is a better adjuvant than tramadol when added to levobupivacaine in supraclavicular brachial plexus block.

\section{References}

1. Ansbro FP. A method of continuous brachial plexus block. The American Journal of Surgery. 1946; 71(6):716-22.

2. Winnie AP, Collins VJ. The Subclavian perivascular technique of brachial plexus anaesthesia. Anaesthesiology 1964; 25:35-63.

3. Neill RS. Postoperative analgesia following brachial plexus block. Br J Anaesth. 1978; 50:379-82.

4. Brown DL, Cahill DR, Bridenbaugh LD. Supraclavicular nerve block:
Anatomic analysis of a method to prevent Pneumothorax. Anesth Analg. 1993; 76:530-4.

5. Moorthy SS, Schmidt SI, Dierdorf SF. A supraclavicular lateral paravascular approach for brachial plexus regional anaesthesia. AnesthAnalg 1991; 72:241-4

6. Valdivia-Sánchez CG, Prieto-Duarte ML. Effectiveness of dexamethasone as an adjuvant in preemptive analgesia for postoperative pain in patients undergoing abdominal surgery. Gac Med Mex. 2017; 153:359-65.

7. Chatopadhyay S, Mitra LG, Biswas BN, Majumder P. Tramadol as an adjuvant for brachial plexus block. J AnaesthClinPharmacol.2007; 23:187-9.

8. Khosa AH, Asad N, Durrani H. Does the addition of Tramadol to local anaesthetic mixture improve the quality of axillary brachial plexus block: a comparative study at the teaching hospital, Dera Ghazi Khan. Age (yrs). Turk J Med Sci 2015; 34: 34-87.

9. Alarasan AK, Agrawal J, Choudhary B, Melhotra A, Uike S, Mukherji A. Effect of dexamethasone in low volume supraclavicular brachial plexus block: A double-blinded randomized clinical study. Journal of anaesthesiology, clinical pharmacology. 2016; 32(2):234 .

10. Arish BT, Babu DD, Lazarus SP, Chandar DD, Balasubramanian S, Kumar KS. Effect of dexamethasone as an adjuvant to local anesthetic in supraclavicular brachial plexus block. Int J Sci Stud. 2016; 3(10):147-53.

11. Baloda R, Bhupal JP, Kumar P, Gandhi GS. Supraclavicular brachial plexus block with or without dexamethasone as an adjuvant to $0.5 \%$ levobupivacaine: A comparative study. Journal of clinical and diagnostic research: JCDR. 2016; 10(6):9.

12. Choi S, Rodseth R, McCartney CJ. Effects of dexamethasone as a local anaesthetic adjuvant for brachial plexus block: a systematic review and meta-analysis of randomized trials. British journal of anaesthesia. 2014; 112(3):427-39.

Copyright: () the author(s), publisher. Academia Anesthesiologica Internationalis an Official Publication of "Society for Health Care \& Research Development". It is an open-access article distributed under the terms of the Creative Commons Attribution Non-Commercial License, which permits unrestricted non-commercial use, distribution, and reproduction in any medium, provided the original work is properly cited.

How to cite this article: Seth M, Das R, Singhal R. Comparison of Dexamethasone and Tramadol as Adjuvant to Levobupivacaine in Supraclavicular Block.Acad. Anesthesiol. Int. 2019;4(2):317-19.

DOI: dx.doi.org/10.21276/aan.2019.4.2.71

Source of Support: Nil, Conflict of Interest: None declared. 